\title{
Interactive comment on "Spatial and Temporal Variation of Bulk Snow Properties in North Boreal and Tundra Environments Based on Extensive Field Measurements" by H.-R. Hannula et al.
}

Anonymous Referee \#2

Received and published: 24 February 2016

Please find my comments in attachment.

Please also note the supplement to this comment:

http://www.geosci-instrum-method-data-syst-discuss.net/gi-2015-37/gi-2015-37-RC2-

supplement.pdf

Interactive comment on Geosci. Instrum. Method. Data Syst. Discuss., doi:10.5194/gi-201537, 2016. 